\title{
FUEL PUMP MODULE NOISE OPTIMIZATION THROUGH DESIGN OF EXPERIMENTS
}

\author{
Thiago Aparecido Rehder Rossetti, Marcos Paulo Del Passo e Filipe Berti Geremias \\ Robert Bosch Ltda \\ E-mails: thiago.rossetti@br.bosch.com,marcos.passo@br.bosch.com e \\ filipe.geremias@br.bosch.com
}

\begin{abstract}
The automotive components NVH levels are increasingly restricted due the improvement search to reduce the overall noise. Generally, the noise is just detected in advance phases of the projects and consequently the reaction time is a problem.

For the Fuel Pump Module, there is no validated simulation to prevent the noise behavior before samples manufacturing. The result of this scenario is a late assessment of noise in bench and / or vehicles.

In certain Fuel Pump Module application, was detected an excessive noise level in high frequency range on test bench. At this case the Noise failure mode is completely new when compared for other Bosch Fuel pump Module. Knowing that the time is one of the main restrictions for automotive projects was necessary a fast approach to develop an optimized noise improvement performance.
\end{abstract}

This paper aims to describe a noise evaluation methodology based on Design of Experiments.

\section{INTRODUCTION}

Main task of fuel pump module (FPM) is delivering of fuel to engine in given quantity and with given pressure in every condition. FPM is placed inside the tank (Figure 1).

FPM generally consists of following parts (Figure 2 and 3), which fulfill different requirements:

- Fuel pump - delivers fuel from a pot to an engine, feeds a jet pump

- Reservoir - serves as a fuel retainer for fuel pump

- Strainer - filters fuel going to the fuel pump

- Jet pump - sucks fuel from tank to reservoir

- Flange - interface between inside and outside of tank

- Pressure regulator - regulates pressure of fuel going to the engine

- Fuel level sensor - measures how much fuel is in the tank 


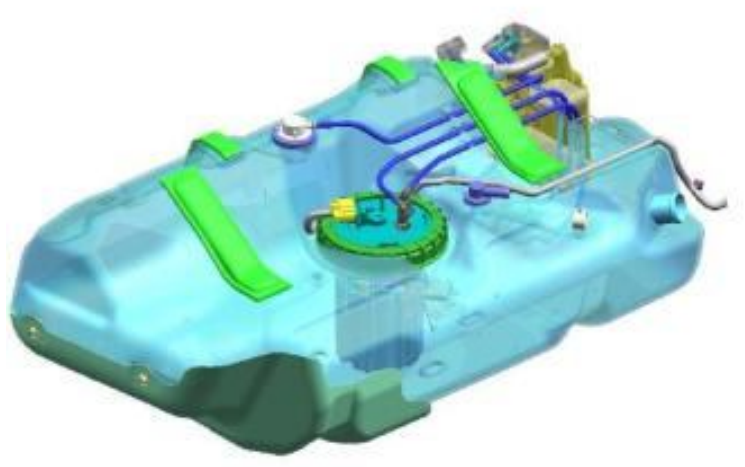

Figure 1. FPM placed inside the tank

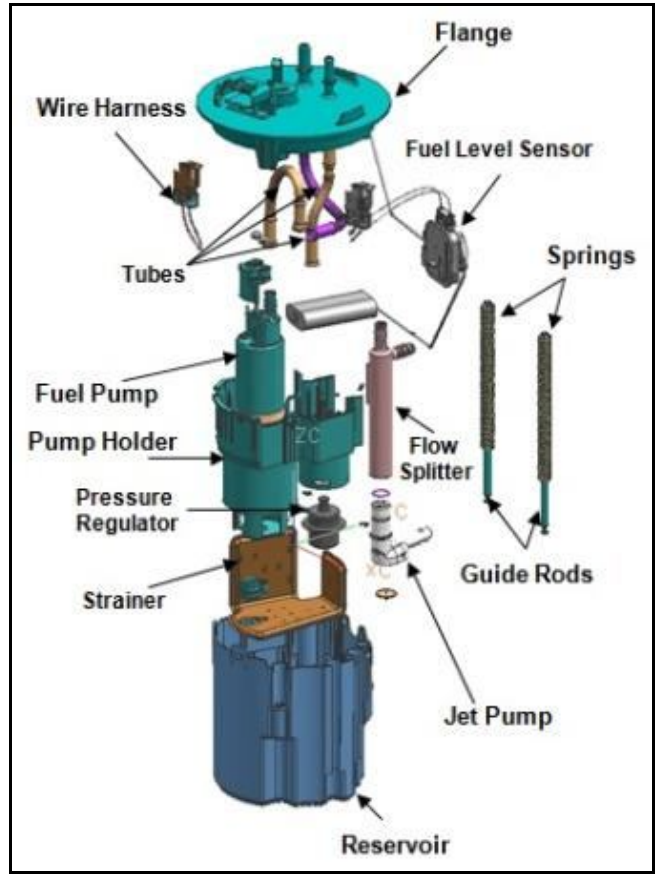

Figure 2. FPM exploded view

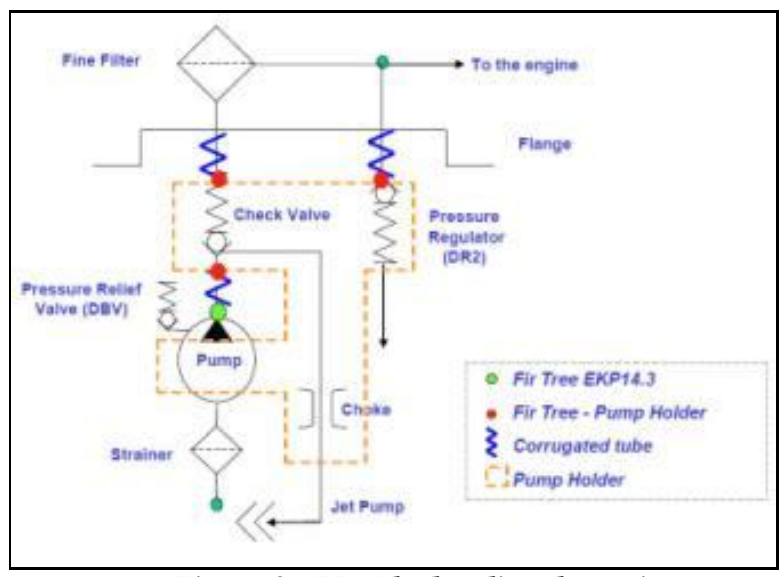

Figure 3. FPM hydraulic schematic 


\section{NOISE REQUIREMENTS}

For the new FPM projects, the customer noise requirements are increasingly restricted. An example of these components targets is a noise evaluation $200 \mathrm{~mm}$ above Flange. Figure 4 shows a typically customer target for this test.

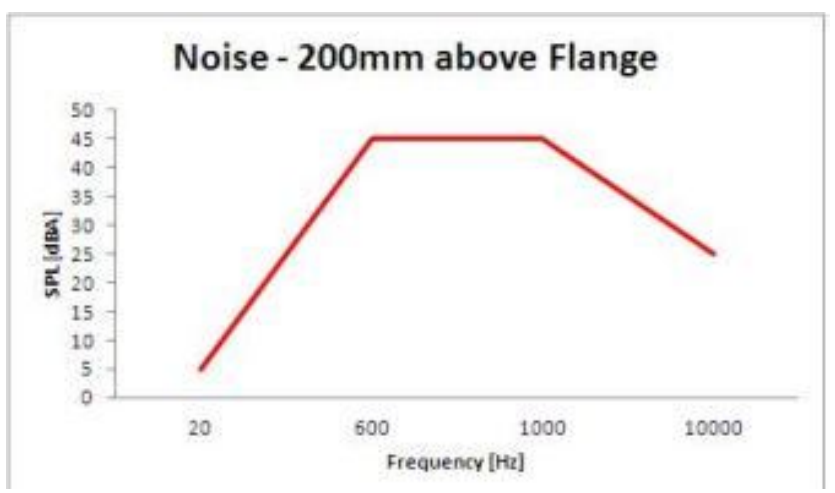

Figure 4. FPM noise requirement (component level)

During the design validation of a new FPM project, it was faced a deviation of the noise requirement. A high frequency peak, around $6 \mathrm{kHz}$ range, was indentified in component level (figure 5). The same sample was evaluated in vehicle level and the high peak noise was audible (figure 6), in other words, the noise behavior was not approved by customer.

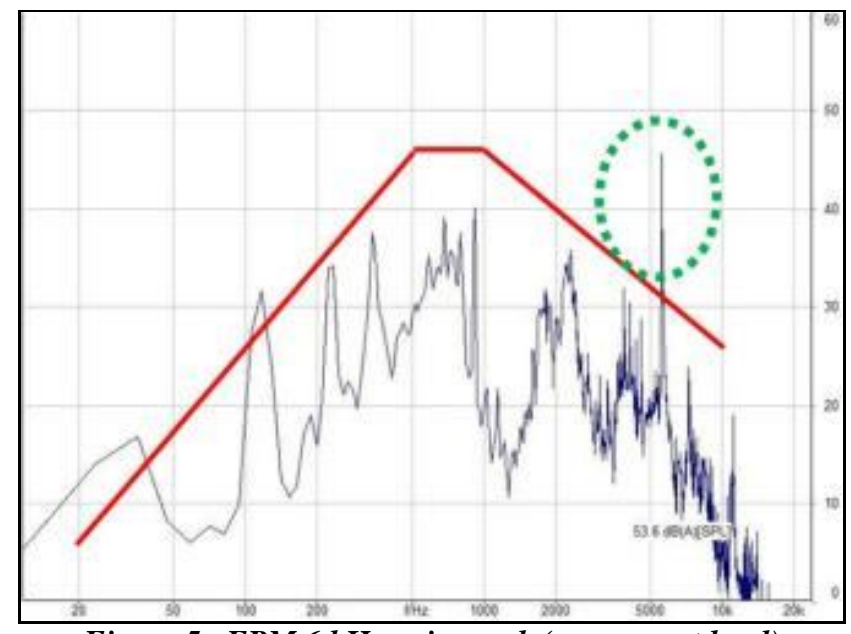

Figure 5. FPM $6 \mathrm{kHz}$ noise peak (component level) 


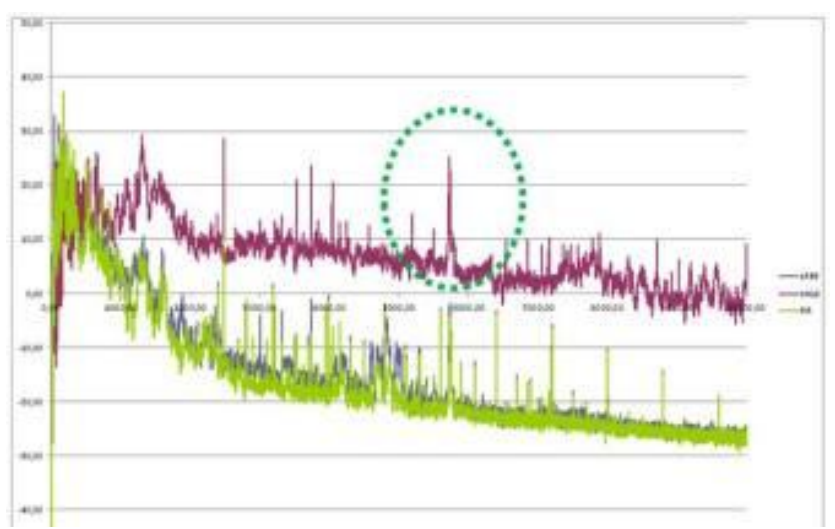

Figure 6. FPM $6 \mathrm{kHz}$ noise peak (vehicle evaluation)

\section{ROOT CAUSE ANALYSIS}

Based on the test results, it was necessary to develop a quick noise evaluation strategy due the time and cost restrictions. To optimize the root cause analysis, the study was divided in sub components.

The first component evaluated was the Fuel Pump. It was required to understand the voltage influence in noise results. A noise sweep test was performed and based on the results no correlation between $6 \mathrm{kHz}$ noise peak and voltage was identified. In the Figure 7, it is clear that the $6 \mathrm{kHz}$ peak remains constant in all voltage range (4 to $14 \mathrm{~V}$ ).

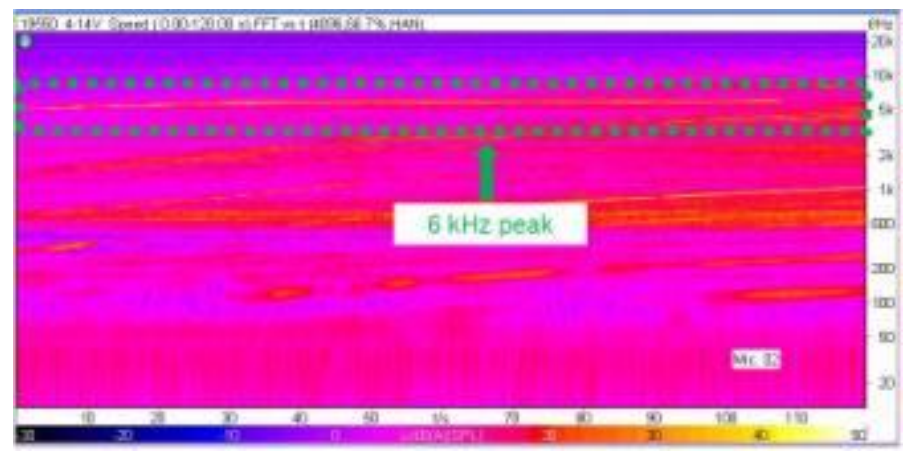

Figure 7. Noise sweep test

In additional to the Fuel Pump evaluation, tangential and radial acceleration were measured and no peaks around $6 \mathrm{kHz}$ were found. With these measurements the Fuel Pump influence was discarded and the failure became related to just to a flow noise.

To identify the responsible for the peak, a teardown was performed together with an objective noise evaluation inside the anechoic chamber. The study was divided in four steps:

1. Record the noise of complete FPM

2. FPM without Pressure regulator

3. FPM without reservoir and return line

4. Sample with Fuel Pump, corrugated feed tube and Flange 


\begin{tabular}{|c|c|c|c|c|c|c|c|c|c|c|}
\hline \multirow[b]{2}{*}{ Tost \# } & \multirow[b]{2}{*}{ Observation } & \multicolumn{9}{|c|}{ Components } \\
\hline & & $\begin{array}{l}\text { Prossure } \\
\text { Regulator }\end{array}$ & Reservoir & $\begin{array}{l}\text { Flow } \\
\text { spluter }\end{array}$ & Jump & $\begin{array}{l}\text { Roturn } \\
\text { Tube }\end{array}$ & $\begin{array}{l}\text { Food } \\
\text { Tube }\end{array}$ & $\begin{array}{l}\text { Pump } \\
\text { Tube }\end{array}$ & Flange & Results \\
\hline 1 & Compiete FPM & $x$ & $\mathrm{x}$ & $x$ & $x$ & $x$ & $x$ & $x$ & $x$ & NOK \\
\hline 2 & $\begin{array}{l}\text { Piessue regiator } \\
\text { assench oussoe } \\
\text { atechoic clarrber }\end{array}$ & . & $x$ & $x$ & $x$ & $x$ & x & x & $x$ & NOK \\
\hline 3 & $\begin{array}{l}\text { Sarnpie wo } \\
\text { reservair and } \\
\text { retum ine }\end{array}$ & . & - & $x$ & $x$ & , & $x$ & $x$ & $x$ & NOK \\
\hline 4 & $\begin{array}{l}\text { Sumpe wh } \\
\text { Pump tibe and } \\
\text { Fuanoe }\end{array}$ & & - & . & - & - & $x$ & . & $\mathrm{x}$ & NOK \\
\hline
\end{tabular}

Figure 8. Noise Teardown test

Even in the step 4, the $6 \mathrm{kHz}$ noise was in the same level as the complete FPM (Figure 8). As the Flange and the Fuel Pump did not have any impact in this peak, the root cause analysis lead for the feed tube as the component to be improved. To confirm this hypothesis, the sample 4 was assembled using a rubber hose instead corrugated feed tube (PA11) and the high peak disappeared.

\section{DESIGN OF EXPERIMENTS}

To improve the corrugated feed tube design, a priority matrix was created. In this case, the environmental and assembly factors need to be analyzed.

Factors:

1. Type of corrugated tube: Straight (low level - current design) / Pre formed (high level)

2. Length of corrugated tube: $147 \mathrm{~mm}$ (low level - current design)/ $193 \mathrm{~mm}$ (high level)

3. Fuel: E100 (low level) / Castrol 9090 (high level)

4. Tube Assembly: normal (low level - current design) / twisted (high level)

5. Voltage: $10 \mathrm{~V}$ (low level) / $14 \mathrm{~V}$ (high level)

For each factor were defined a low and high level, based on the application. The following fully factorial $2^{5}$ DOE was defined (table 1): 


\begin{tabular}{|c|c|c|c|c|c|}
\hline Test & Type Tube & Length [mm] & Fuel & Tube Assembly & Voltage [V] \\
\hline 1 & Pre Formed & 147 & Castrol & Twisted & 10 \\
\hline 2 & Straight & 197 & Castrol & Twisted & 10 \\
\hline 3 & Straight & 147 & Castrol & Twisted & 10 \\
\hline 4 & Pre Formed & 197 & E100 & Twisted & 10 \\
\hline 5 & Straight & 147 & Castrol & Normal & 10 \\
\hline 6 & Pre Formed & 147 & E100 & Twisted & 10 \\
\hline 7 & Straight & 197 & E100 & Twisted & 14 \\
\hline 8 & Straight & 147 & E100 & Normal & 10 \\
\hline 9 & Straight & 147 & E100 & Twisted & 10 \\
\hline 10 & Pre Formed & 147 & E100 & Normal & 10 \\
\hline 11 & Pre Formed & 197 & E100 & Twisted & 14 \\
\hline 12 & Pre Formed & 147 & Castrol & Twisted & 14 \\
\hline 13 & Straight & 197 & $E 100$ & Normal & 10 \\
\hline 14 & Straight & 197 & E100 & Twisted & 10 \\
\hline 15 & Pre Formed & 147 & Castrol & Normal & 10 \\
\hline 16 & Pre Formed & 197 & Castrol & Normal & 10 \\
\hline 17 & Straight & 197 & Castrol & Normal & 10 \\
\hline 18 & Pre Formed & 197 & Castrol & Twisted & 14 \\
\hline 19 & Straight & 147 & Castrol & Normal & 14 \\
\hline 20 & Straight & 147 & Castrol & Twisted & 14 \\
\hline 21 & Straight & 197 & E100 & Normal & 14 \\
\hline 22 & Pre Formed & 147 & E100 & Twisted & 14 \\
\hline 23 & Pre Formed & 147 & Castrol & Normal & 14 \\
\hline 24 & Pre Formed & 197 & Castrol & Twisted & 10 \\
\hline 25 & Straight & 197 & Castral & Normal & 14 \\
\hline 26 & Straight & 197 & Castrol & Twisted & 14 \\
\hline 27 & Straight & 147 & E100 & Twisted & 14 \\
\hline 28 & Pre Formed & 197 & E100 & Normal & 14 \\
\hline 29 & Pre Formed & 147 & E100 & Normal & 14 \\
\hline 30 & Straight & 147 & E100 & Normal & 14 \\
\hline 31 & Pre Formed & 197 & E100 & Normal & 10 \\
\hline 32 & Pre Formed & 197 & Castrol & Normal & 14 \\
\hline
\end{tabular}

\section{DOE RESULTS}

The tests were performed recording the maximum noise peak between the 5700 and $6300 \mathrm{~Hz}$ after 30 seconds.

The Pareto Chart (Figure 9) shows the main effects found in the evaluation. The top five effects were:

1. Type of Fuel

2. Correlation between Voltage and Fuel

3. Voltage

4. Tube Length

5. Correlation between Type of tube, Fuel, Tube assembly and voltage 


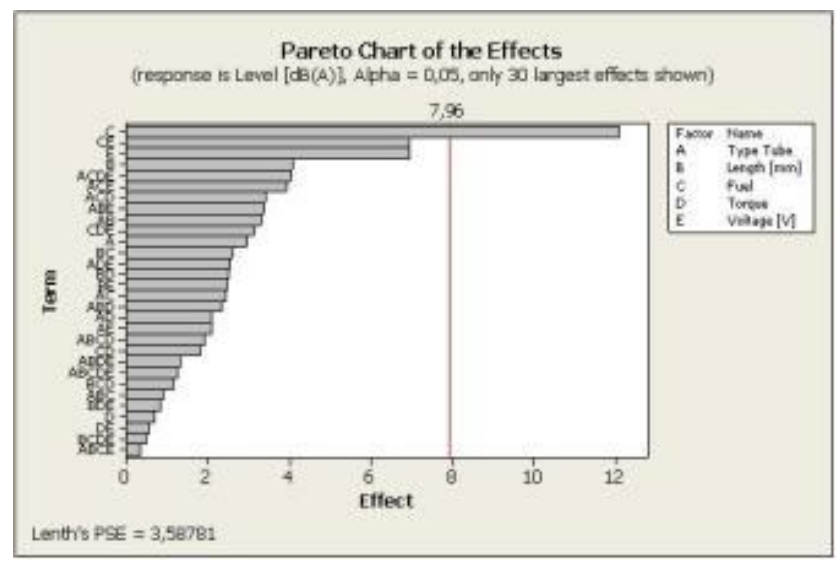

Figure 9. Pareto Chart of the Effects

Using the Main Effects Plot for Level (Figure 10), it was possible to evaluate the influence of level for each factor. The higher the slope of the curve, the greater is its factor influence. For this evaluation, the fuel and voltage presented greater slope. However, for these factors, no improvements are possible. They are costumers requirements and shall be respected.

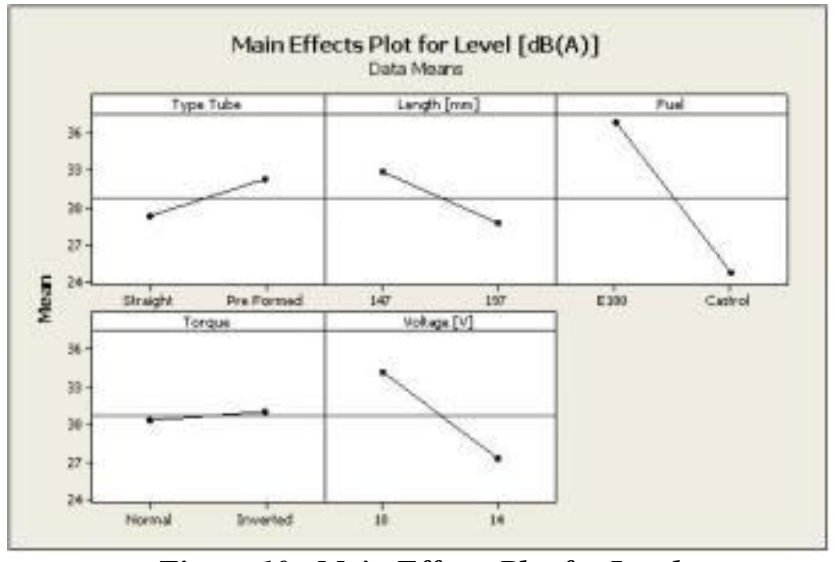

Figure 10. Main Effects Plot for Level

No higher interaction between the factors was detected during the DOE (Figure 11).

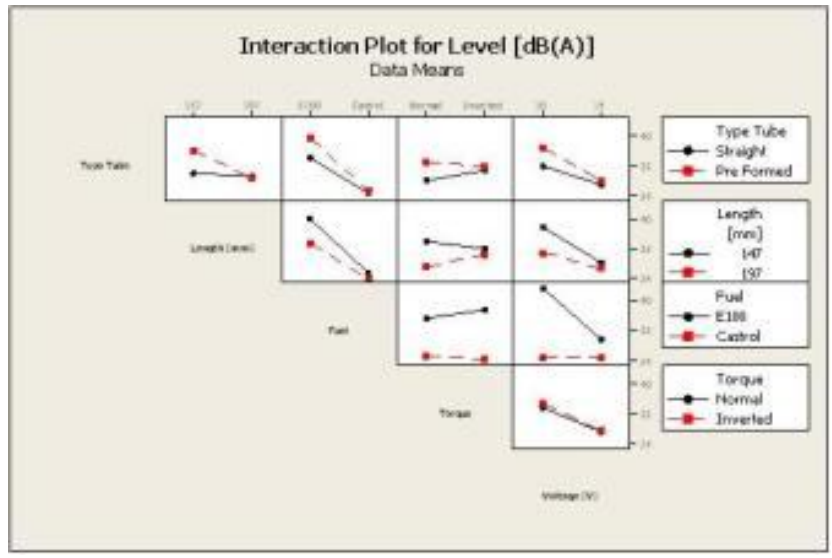

Figure 11. Interaction Plot for Level 
Analyzing the DOE results, the low noise level was detected in the sample assembled with the following configuration:

- Length of tube: $197 \mathrm{~mm}$;

- Tube: Straight;

- Tube assembly: Normal;

- Voltage: $14 \mathrm{~V}$;

- Fuel: Castrol 9090;

Summarizing the study, it is possible to ensure that the tube stiffness (length, type and way of assembly) has influence in the noise. Unfortunately, the tube with $197 \mathrm{~mm}$ length is not possible to be used in serial production in this application due lay out restriction (FPM height work range not respected). As the noise issue need to be solved a new DOE round need to be run. Using the maximum allowed application tube length as restriction, the tested tubes were defined:

- Corrugated tube $-155 \mathrm{~mm}$ length;

- Corrugated tube $-160 \mathrm{~mm}$ length;

- Corrugated tube $-173 \mathrm{~mm}$ length;

- Rubber Hose $173 \mathrm{~mm}$;

- Prototype - Mixed Tube 173mm (corrugated and smooth - Figure12);

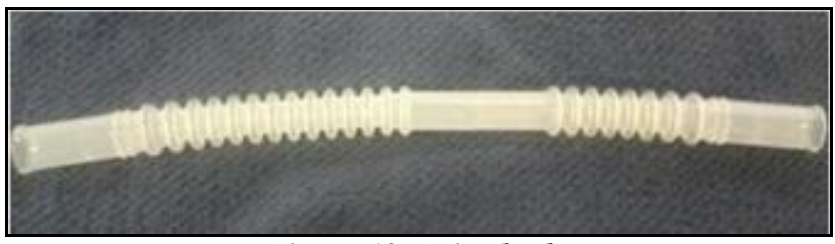

Figure 12. Mixed tube

The tests were performed exactly as the first round, record the maximum noise peak between the 5700 and $6300 \mathrm{~Hz}$ after 30 seconds. In the Figure 13 it is possible to evaluate the tube influence. Despite the great result found using a rubber hose, the impact in FPM assembly line invalidates this concept. The mixed tube presents results better than others tubes and it was chosen as the final concept.

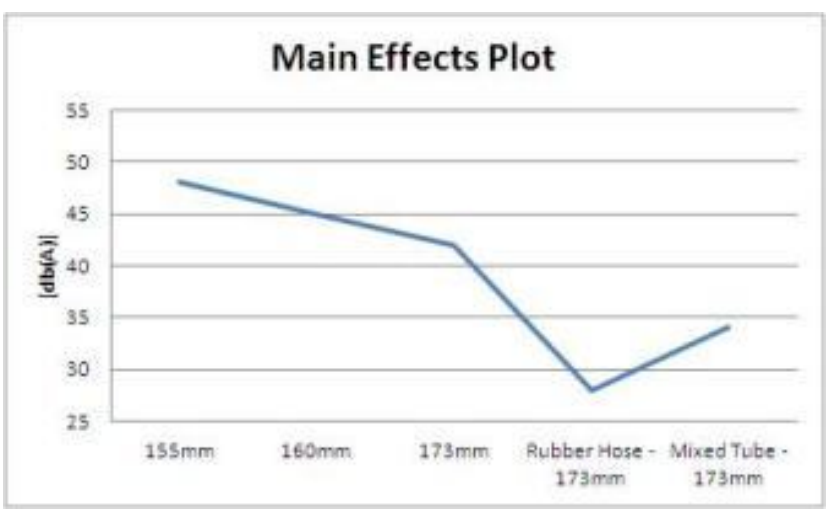

Figure 13. Round 2 results 


\section{RESULTS CONFIRMATION}

To ensure the effectiveness of the concept, a complete noise evaluation was performed following the customer standard using 10 samples. The average noise of all tested samples is showed in the Figure 14. The worst sample of this batch was evaluated in the vehicle and the customer approved the concept.

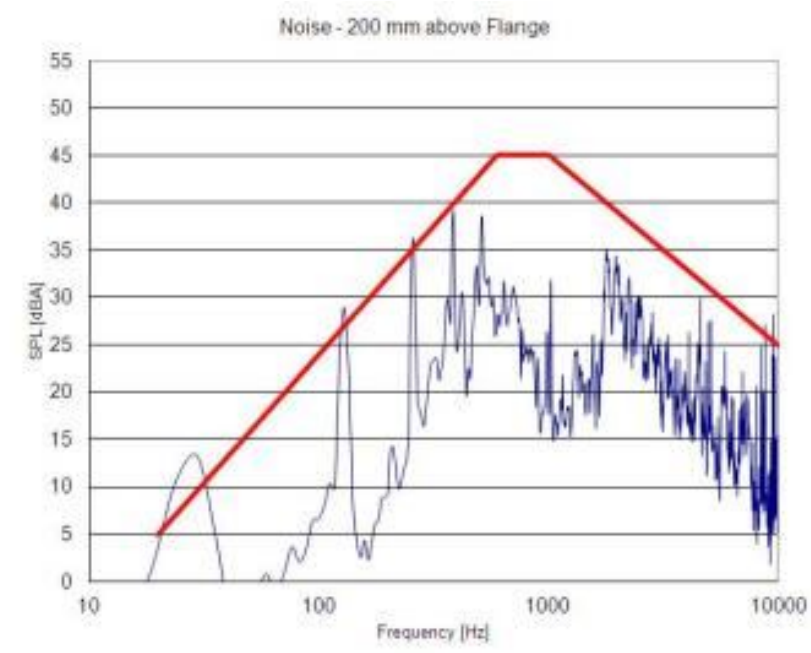

Figure 14. FPM assembled with mixed tube

\section{SUMMARY/CONCLUSIONS}

Requirements are becoming restricted for all customers and a good practice is to perform the noise assessment in the beginning of project due the reaction time. Some noise issues take long time to be concluded and impact directly in projects milestones. The DOE together with the company know-how reduce the time to achieve an acceptable noise behavior and show new opportunities to future FPM projects.

\section{REFERENCES}

1. Internal documents by Robert Bosch 